\title{
Clinico-epidemiological profile and diagnostic procedures of pediatric tuberculosis in a tertiary care hospital of western Nepal-a case-series analysis
}

Chandrashekhar T Sreeramareddy ${ }^{1,5^{*}}$, Narayan Ramakrishnareddy ${ }^{2}$, Ravi K Shah ${ }^{3}$, Ramkaji Baniya ${ }^{3}$, Pradipta K Swain ${ }^{4,6}$

\begin{abstract}
Background: Changing epidemiology and diagnostic difficulties of paediatric tuberculosis (TB) are being increasingly reported. Our aim was to describe clinico-epidemiological profile and diagnostic procedures used for paediatric TB.

Methods: A retrospective case-series analysis was carried out in a tertiary care teaching hospital of western Nepal. All pediatric TB (age 0-14 years) patients registered in DOTS clinic during the time period from March, 2003 to July, 2008 were included. Medical case files were reviewed for information on demography, clinical findings, investigations and final diagnosis. Analysis was done on SPSS package. Results were expressed as rates and proportions. Chi square test was used to test for statistical significance.

Results: About 17.2\% (162/941) of TB patients were children. Common symptoms were cough, fever and lymph node swelling. The types of TB were pulmonary TB (46.3\%, 75/162), followed by extra-pulmonary TB (41.4\%, 67/162). Twelve patients (7.4\%) had disseminated TB. Distribution of types of TB according to gender was similar. PTB was common in younger age than EPTB which was statistically significant. EPTB was mainly localized to lymph node $(38,50.7 \%)$, and abdomen $(9,12 \%)$. Five main investigations namely Mantoux test, BCG test, chest radiograph, erythrocyte sedimentation rate (ESR) and fine needle aspiration cytology (FNAC) or biopsy were carried out to diagnose TB.

Conclusions: Paediatric TB in both pulmonary and extrapulmonary forms is a common occurrence in our setting. Age incidence according to type of TB was significant. Diagnosis was based on a combination of epidemiological and clinical suspicion supported by results of various investigations.
\end{abstract}

\section{Background}

World Health Organization (WHO) reports that about two billion i.e. nearly one third of the world's population is currently infected with mycobacterium tuberculosis. Developing countries account for $95 \%$ of the burden of tuberculosis (TB) and 99\% of the TB mortality reported worldwide [1]. It is estimated that about $9 \%$ of the TB cases globally occur among children less than 15 years

\footnotetext{
* Correspondence: chandrashekharats@yahoo.com

'Department of Community Medicine, Manipal Teaching Hospital, Manipal

College of Medical Sciences, Pokhara, Nepal

Full list of author information is available at the end of the article
}

of age. The same proportion in low-income countries is $15 \%$ [2]. TB among children is important for public health professionals since it is an indicator of the recent transmission of TB in the community. Contact investigations of pediatric TB patients may lead to improved case-finding among adult patients [3]. However, the national TB control programs lay more emphasis on sputum smear-positive adult TB cases since they are highly infectious. As a result childhood TB is often neglected by TB control programs due to the difficulties in confirming diagnosis, over estimating the protective efficacy of BCG vaccine [4]. Moreover, diagnosis of TB
C Biomed Central

() 2010 Sreeramareddy et al; licensee BioMed Central Ltd. This is an Open Access article distributed under the terms of the Creative Commons Attribution License (http://creativecommons.org/licenses/by/2.0), which permits unrestricted use, distribution, and reproduction in any medium, provided the original work is properly cited. 
among children may be more challenging in resourcepoor settings like Nepal. There has been an increasing concern about TB among children who are HIV seropositive [5]. Studies from Taiwan, USA and Saudi Arabia have reported about epidemiology and clinical features childhood TB [6-9]. Clinical presentation may depend on the epidemiological situation of TB and HIV in that country. Diagnostic methods followed for childhood TB may vary depending on the available resources in the health-care setting.

In Nepal, about $45 \%$ of the total population is infected with TB and an estimated 20,000 new infectious cases of TB are reported each year. Sentinel surveys have reported that the rate of HIV seropositivity in all age groups has increased from $0.6 \%$ in $1995 / 96$ to $2.4 \%$ in 2006/07[10]. However, studies on epidemiology, clinical profile and diagnostic methods of childhood TB from low-income countries like Nepal are lacking. Therefore, we carried out this study to describe the clinico-epidemiological profile and diagnostic processes of pediatric TB patients.

\section{Methods}

\section{Study setting}

Manipal Teaching Hospital (MTH) is a tertiary care hospital which is affiliated to Manipal College of Medical Sciences (MCOMS). MTH serves patients from Pokhara city and remote hilly areas of western Nepal. In March 2003, DOTS (Directly Observed Treatment, Short course) clinic was started in MTH as a part of involvement of medical colleges in TB control under the National TB Program (NTP) of Nepal. Guidelines of NTP are followed for diagnosis of TB in all the clinical departments of MTH. TB patients diagnosed in various clinical departments of MTH are referred to DOTS clinic where they are registered and receive treatment according to the guidelines of NTP.

\section{Data collection}

Ethical clearance was obtained from ethical committee of MCOMS and permission to access medical records was obtained from medical superintendent of MTH. All pediatric TB (age 0-14 years) patients registered in DOTS clinic during the time period from March, 2003 to July, 2008 were included for the study. A list of patients with their hospital numbers was obtained from the DOTS clinic and original medical case files were traced from medical records department. Medical case files, reports of chest radiographs and laboratory investigations were reviewed to obtain the necessary information about diagnosis of TB. The information collected included symptoms and their duration, findings of sputum examination or gastric lavage for the presence of acid fast bacilli (AFB), localization of lesions in the chest radiographs, details of laboratory and/or histopathological examination for diagnosis for extra-pulmonary TB. We also gathered information about household contact with an active case of pulmonary TB, tests for HIV infection, history of BCG vaccination and/or presence of BCG scar (at least four millimeters in size), Mantoux test and BCG test/accelerated BCG response (When $\mathrm{BCG}$ is given to a child with $\mathrm{TB}$, the reaction occurs at the site of vaccination within $48-72$ hours as compared to usual late reaction which occurs after 3-6 weeks in a child without TB. Appearance of a papule or an induration more than $5 \mathrm{~mm}$ in size at the test site was

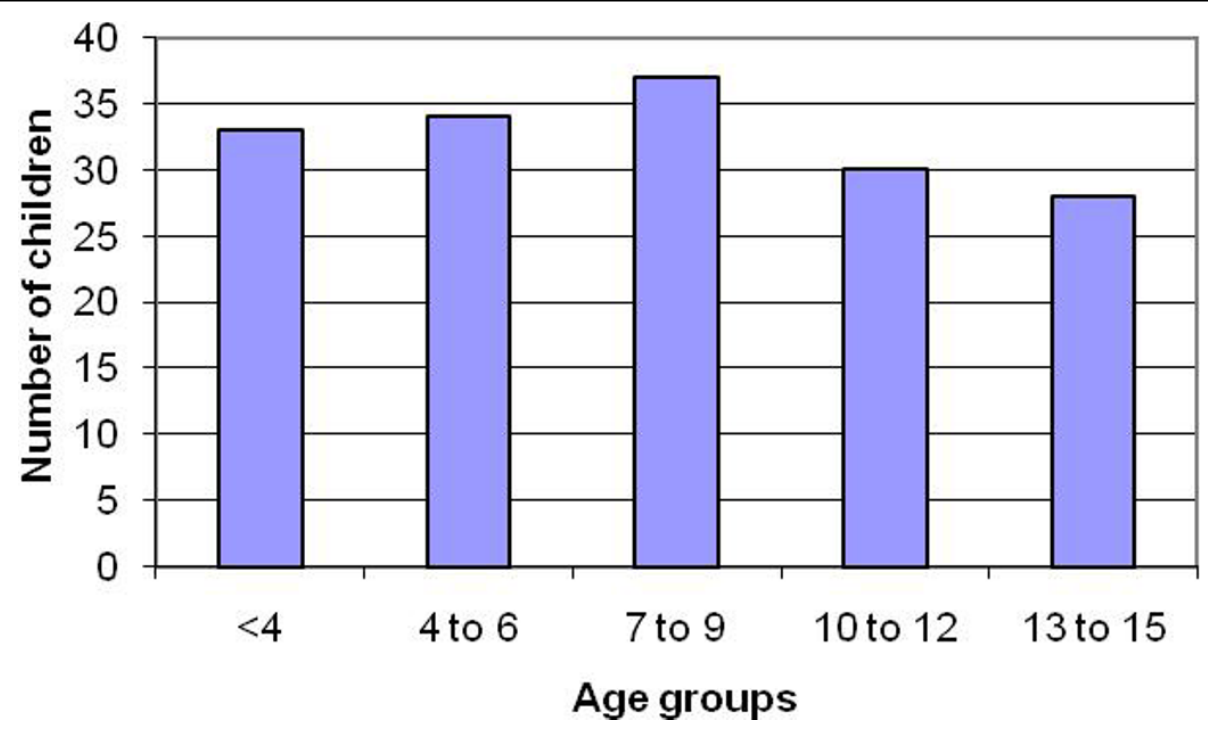

Figure 1 Age distribution of all TB patients. 
Table 1 Presenting symptoms of the children diagnosed as Tuberculosis

\begin{tabular}{ll}
\hline Complaint & Number (\%)* \\
\hline Fever & $70(43.2)$ \\
\hline Cough & $42(25.9)$ \\
\hline Lymph node swelling & $25(15.4)$ \\
\hline Pain (abdomen, chest etc) & $19(11.7)$ \\
\hline Lailure to thrive & $13(8.0)$ \\
\hline Breathlessness & $11(6.8)$ \\
\hline Discharge from the ear & $7(4.3)$ \\
\hline Weight loss & $5(3.1)$ \\
\hline Redness in the eye & $4(2.5)$ \\
\hline Others & $4(2.5)$ \\
\hline
\end{tabular}

* Each patient may have more than one symptom

considered as positive BCG Test) [11]. For the purpose of our analysis type of TB was classified as isolated pulmonary $\mathrm{TB}$, extra-pulmonary $\mathrm{TB}$, pulmonary $\mathrm{TB}$ with extra-pulmonary TB (only one extrapulmonary site) and disseminated (pathology in more than two sites) and miliary TB. Data was entered into SPPS version 13 (Statistical Package for Social Sciences) package. Data was presented as rates and proportions. Statistical significance of difference in proportions was tested using chi square test and a p-value less than 0.05 was considered as significant.

\section{Results}

A total 941 TB patients were diagnosed during March 2003 to July 2008 . Of these 178 were children aged 14 years or less (i.e. $18.9 \%$ of all cases were childhood TB). These cases were diagnosed and referred to DOTS clinic for treatment. From the list of 178 cases obtained from DOTS register, medical case files of 16 patients could not be traced. Median age of the children was 7.5 years (interquartile range, 4 to 12 years). Age of the patients ranged from 6 months to 14 years. Age distribution of TB patients is shown in figure 1 and was similar in all age groups. Male to female ratio was 1:1 with 81 children in each group. The most common presenting symptoms were fever, cough, lymph node swelling and pain as shown in table 1.

Most common form of TB was pulmonary TB followed by extra-pulmonary TB. Twelve patients were diagnosed as disseminated TB (one child had miliary TB). Distribution of types of TB according to age groups is shown in table 2. Pulmonary TB was common in younger age group as compared to extra-pulmonary TB which was common in older age group. This difference was statistically significant. Distribution of type of TB among male and female patients (data not shown) was not statistically significant (chi square $3.29, \mathrm{p}=0.35$ ). The sites of extrapulmonary $\mathrm{TB}$ are shown in figure 2 . Out of 75 patients who were diagnosed as extra-pulmonary TB (inclusive of combined type); most common sites were lymph node, and abdomen. Less common sites of extra-pulmonary TB were pleura, pericardium, and meninges.

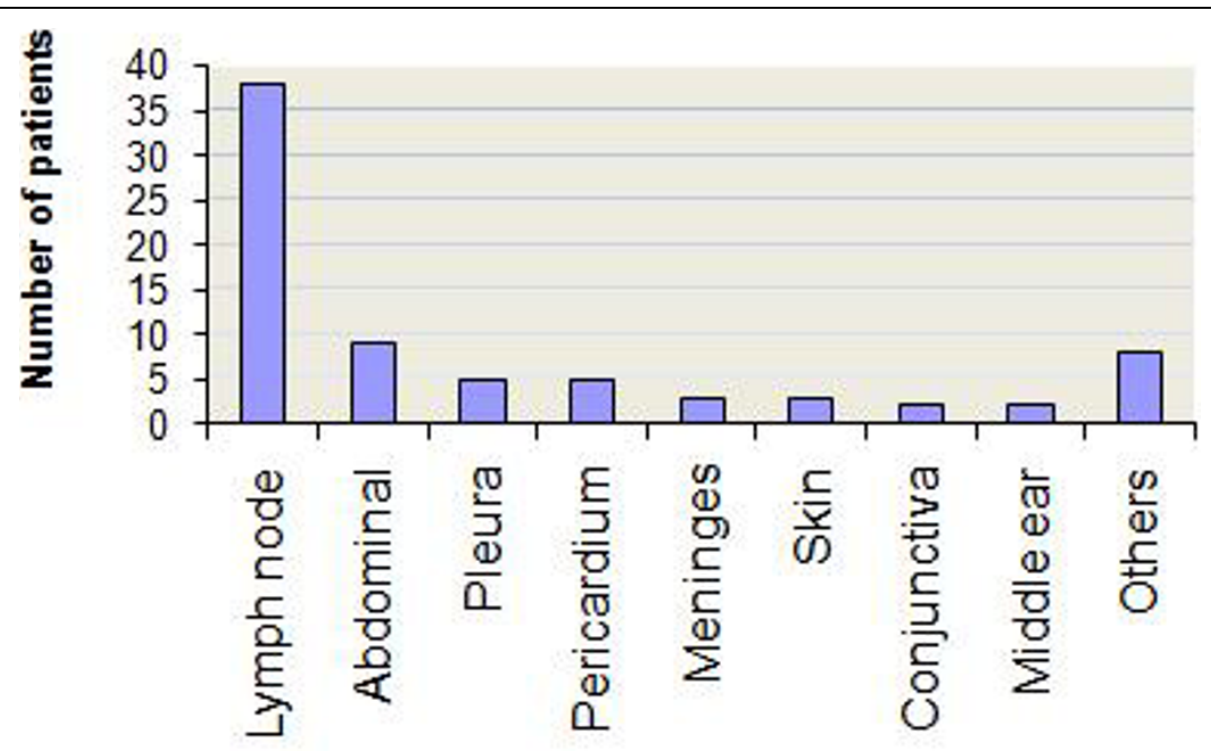

Site

Figure 2 Sites of extra-pulmonary tuberculosis. 
Table 2 Types of Tuberculosis according to age

\begin{tabular}{|c|c|c|c|c|c|}
\hline \multirow[t]{2}{*}{ Age group (Years) } & \multicolumn{4}{|c|}{ Type of tuberculosis (Number and percentage) } & \multirow[t]{2}{*}{ Total } \\
\hline & $\begin{array}{l}\text { Isolated } \\
\text { Pulmonary }\end{array}$ & Isolated Extrapulmonary & $\begin{array}{c}\text { Combined } \\
\text { (PTB + EPTB) }\end{array}$ & $\begin{array}{c}\text { Disseminated/ } \\
\text { Miliary }\end{array}$ & \\
\hline$<4$ & $26(34.7)$ & $4(6.0)$ & - & $3(25.0)$ & $33(20.4)$ \\
\hline $4-6$ & $17(22.7)$ & $14(20.9)$ & $1(12.5)$ & $2(16.7)$ & $34(21.4)$ \\
\hline $7-9$ & $12(16.0)$ & $20(29.9)$ & - & $5(41.7)$ & $37(22.8)$ \\
\hline $10-12$ & $10(13.3)$ & $14(20.9)$ & $5(62.5)$ & $1(8.3)$ & $30(18.5)$ \\
\hline $13-15$ & $10(13.3)$ & $15(22.4)$ & $2(25.0)$ & $1(8.3)$ & $28(17.3)$ \\
\hline Total & 75 (100) & $67(100)$ & $8(100)$ & $12(100)$ & $162(100)$ \\
\hline
\end{tabular}

Chi square $=36.1, \mathrm{p}<0.0001$

Immunisation history for BCG and/or presence of BCG scar was present in $93(57.4 \%)$ patients and absent in $20(12.3 \%)$ patients. For $49(30.2 \%)$ patients information was not available. Out of 162 cases reviewed, HIV spot test was done for $36(22.2 \%)$ patients and was positive in eight children. History of contact with a case of TB was available for only $126(77.7 \%)$ out of 162 patients. For remaining 36 (22.2\%) patients data was not available. Of these 126 patients for whom information about history of contact was available, only 38 patients had positive history of contact.

Upon review of the investigations carried out for diagnosis we found that five main investigations namely Mantoux test, BCG test (accelerated BCG response), chest radiograph, ESR and FNAC or biopsy were carried out. Table 3 shows various investigations carried out according to type of TB. Microscopy for AFB was done on samples of sputum, gastric lavage and also used pus, ear swab or cerebrospinal fluid. However, microscopy was positive only in a small proportion $(<20 \%)$ of children in both pulmonary and extra-pulmonary TB and none in disseminated TB. Sputum for AFB was not done for 13 of 58 children who were aged above 10 years. Mantoux test was done for 57 children diagnosed as PTB and $66 \%$ of them had a positive test (induration of at least 10 millimeter was considered as positive) [12]. Mantoux test was done for 45 children diagnosed as ЕРTB and $71 \%$ of the children were tested positive. However, BCG test was done for only 31 children diagnosed as PTB and for 15 children diagnosed as EPTB. Overall, BCG test was done for 49 patients and was positive in more than $90 \%$ of both PTB and EPTB patients. Chest radiograph was positive in $94 \%(72 / 76)$ of PTB patients and 63\% (36/57) of EPTB patients. Lymph node TB was mainly diagnosed by FNAC. FNAC was done for 38 children and was positive for TB in 32 of them. For other (abdominal, pleural, pericardial, meningeal) extrapulmonary manifestations of TB, diagnosis was based on positive findings of special investigations like ultrasound (16/18) lumbar puncture (2/2), biopsy of the skin (1/1). Middle ear TB was diagnosed based on presence of AFB in ear swab. Phlyctenular keratoconjunctivtis was diagnosed based on positive Mantoux test and/or positive chest $\mathrm{x}$-ray.

\section{Discussion}

In our analysis of medical case files/records we found that childhood TB accounted for nearly a fifth of all TB

Table 3 Diagnostic procedures/investigations carried out

\begin{tabular}{|c|c|c|c|}
\hline \multirow[t]{2}{*}{ Investigations or diagnostic procedures } & \multicolumn{3}{|c|}{$\begin{array}{c}\text { Type of tuberculosis (Figures show number positive out of number of patients on whom } \\
\text { procedure/investigation done) }\end{array}$} \\
\hline & $\begin{array}{l}\text { Pulmonary } \\
(\mathrm{n}=83)\end{array}$ & Extra-pulmonary $(n=75)$ & $\begin{array}{l}\text { Disseminated } \\
\quad(n=12)\end{array}$ \\
\hline Mantoux test & $38 / 57$ & $32 / 45$ & $9 / 10$ \\
\hline BCG test & $29 / 31$ & $14 / 15$ & $3 / 3$ \\
\hline Chest radiograph & $72 / 76$ & $36 / 57$ & $8 / 9$ \\
\hline Elevated ESR & $32 / 55$ & $20 / 54$ & $7 / 10$ \\
\hline Gastric lavage for AFB & $3 / 27$ & $1 / 12$ & $0 / 6$ \\
\hline Sputum for AFB & $5 / 36$ & $2 / 37$ & $0 / 2$ \\
\hline FNAC & - & $32 / 38$ & - \\
\hline ultrasound & - & $16 / 18$ & - \\
\hline Biopsy & - & $7 / 7$ & - \\
\hline lumbar puncture for cerebrospinal fluid analysis & - & $2 / 2$ & - \\
\hline
\end{tabular}


patients. Common symptoms were fever, cough and lymph node swelling. Though distribution of all forms of TB was similar across all age groups, there was slight peak for pulmonary TB among children aged less than four years and extra-pulmonary TB after 10 years of age. Most common extra-pulmonary site was lymph node (mainly cervical). For the diagnosis of pulmonary TB, chest radiograph, Mantoux and BCG tests were done while extra-pulmonary $\mathrm{TB}$ was diagnosed using various diagnostic procedures.

Childhood TB is often neglected in high-burden countries. It is thought that children suffer from TB less often and less severely than the adults [13]. On the contrary, in high-burden countries a considerable proportion of TB patients are children and $\mathrm{TB}$ related morbidity and mortality is high among children [14]. Despite the decrease in TB burden since $1960 \mathrm{~s}$ there was resurgence during the nineties due to HIV epidemic [15]. The age incidence for all forms TB showed a bimodal distribution in two studies from Taiwan [6,7]. In our analysis, we did not find such pattern but we found two separate peaks for PTB $(<4$ years $)$ and EPTB (after 10 years). One possible explanation for such pattern may be higher TB prevalence in Nepal. A higher frequency of exposure to infectious patient at an early age could have resulted in pulmonary disease. It is also possible that BCG vaccination may have protected them from serious extra-pulmonary forms of TB [16]. This is supported by our data that nearly $60 \%$ of the children had received BCG vaccine and/or BCG scar was present. Some studies have reported that BCG may protect children from TB infection also $[17,18]$. However, studies from other countries have reported that young children are more likely to develop extra-pulmonary TB $[19,20]$. In our analysis, we found that $55 \%$ of all $\mathrm{TB}$ patients had extra-pulmonary involvement and 10/12 patients of disseminated or miliary TB were younger than 10 years and most of the children who had extra-pulmonary TB were older than 4 years.

Few studies have suggested about increasing trends of extra-pulmonary manifestations among children as well adults $[19,20]$. Most common extra-pulmonary site in our setting was lymph node similar to studies reported from elsewhere [20-22]. The second common site was gastrointestinal. Increasing trend for extra-pulmonary TB may be attributed to HIV infection. We cannot attribute a higher proportion of EPTB to HIV infection from our data since HIV testing was only done for a fifth of all patients. Routine HIV testing is not done for TB suspects in our setting. Rather, HIV testing is done only on the grounds of clinical and/or epidemiological suspicion. Higher frequency of extra-pulmonary TB could be due to transmission of bovine TB in an agrarian country like Nepal where proximity with livestock is common. This could also be the reason for gastrointestinal system being second common site of extra-pulmonary TB. However, there is a lack of adequate evidence to support this hypothesis.

In our analysis, $12(7.4 \%)$ children had disseminated $\mathrm{TB}$ which is a cause for concern. It is noteworthy that most of these children were also younger than 10 years. Non-specific manifestations of pediatric TB, lack of diagnostic facilities and lack of suspicion of TB among physicians in smaller health facilities may be the reasons for presenting to a teaching hospital at later stages of disease. In a large proportion of patient files symptoms were only listed without recording their duration since onset. Therefore, we could not assess if there was a longer time duration since onset of symptoms until diagnosis was made in our hospital.

It is a well known fact that diagnosis of TB in pediatric age group is difficult [23]. Our analysis about the diagnostic procedures revealed that there was no single diagnostic procedure which could be used as a gold standard test. Most children underwent many diagnostic procedures before a final diagnosis of $\mathrm{TB}$ was made. There are some notable points to be made about diagnostic procedures followed in our setting. The diagnostic criteria for both forms of TB were not clear in the case files. PTB was diagnosed mainly based on chest radiograph, Mantoux test, BCG test and ESR. Special investigations were done for EPTB patients but diagnostic criteria were not explicit in the case files. However, we read the reports of chest radiographs, ultrasound, biopsies etc to corroborate with the final diagnosis. Chest radiograph was used for both pulmonary and extra-pulmonary though its reliability as diagnostic tool is questionable [24]. A high proportion (94\%) of chest radiographs were interpreted as positive for patients diagnosed as PTB. Clinical suspicion and evidence from positive results of other diagnostic tests may have prompted the physicians to interpret chest radiographs as positive for TB. Sputum or other specimens for presence of acid fast bacilli which is gold standard test for adult TB was occasionally used. We emphasize this point since sputum AFB was not done for all children aged above 10 years. Mantoux (skin) test was done on a fairly high proportion of patients with all forms of $\mathrm{TB}$ and about two-thirds of those tested were interpreted as positive. There is a difficulty in interpreting a positive Mantoux test in our setting where universal BCG vaccination is done during neonatal period [25]. Though negative Mantoux test does not rule out TB, a positive test may be a useful diagnostic tool in a resource-limited setting like ours. Extrapulmonary TB was diagnosed mainly by FNAC and biopsy. These findings emphasize about the diagnostic difficulties faced by physicians in resource-limited settings. Such findings have been reported from other countries as well $[24,26,27]$. 
Our study had a few limitations. Some important clinical and demographic information were incomplete or missing from the medical case records. When demographic information was not available in medical case files, we cross-checked patient's name with hospital number or outpatient registration number and also with DOTS center register to find the information about age and gender. There was no means to find missing clinical data as we did a retrospective analysis. Very important information about weight and/or height was not available for most of the children and was not included for this analysis. With best of our efforts we could not trace a few medical records from the archives.

\section{Conclusion}

Pediatric TB is common in our setting. Common extrapulmonary sites were lymph nodes and gastrointestinal system. Diagnosis of TB was not systematic and mostly based on a combination of epidemiological and clinical suspicion supported by results of various investigations.

\section{Acknowledgements}

All the authors thank staff at Medical records department, Manipal Teaching Hospital for their assistance in retrieving the medical case files. We also thank Mrs. Gunisha Purja for her assistance providing us the list of TB patients registered at the DOTS centre. This study did not receive any funding.

\section{Author details}

${ }^{1}$ Department of Community Medicine, Manipal Teaching Hospital, Manipal College of Medical Sciences, Pokhara, Nepal. ${ }^{2}$ Department of Community Medicine, Bangalore Medical College and Research Institute, Bangalore, India. ${ }^{3}$ Manipal College of Medical Sciences, Pokhara, Nepal. ${ }^{4}$ Department of Pediatrics, Manipal Teaching Hospital, Manipal College of Medical Sciences, Pokhara, Nepal. ${ }^{5}$ Department of Community Medicine, Melaka-Manipal Medical College, Melaka, Malaysia. ${ }^{6}$ Department of Pediatrics, Melaka-Manipal Medical College, Melaka, Malaysia.

\section{Authors' contributions}

CTS contributed to the study design, assisted in the data collection, and drafted first version manuscript for publication. NRR Assisted in study design and co-drafted the manuscript for publication. RKS reviewed the medical case files, conducted the data analysis and prepared the results. $\mathbf{R B}$ reviewed the medical case files, conducted the data analysis and prepared the results. PKS assisted in study design, prepared the case record form, and revised the earlier versions of the manuscript. All authors read and approved the final manuscript to be submitted for Publication.

\section{Competing interests}

The authors declare that they have no competing interests.

Received: 22 November 2009 Accepted: 9 August 2010

Published: 9 August 2010

\section{References}

1. WHO Report: WHO report Global tuberculosis control surveillance, planning, financing. 2003 [http://www.who.int/tb/publications/ global_report/2008/en/].

2. Dolin PJ, Raviglione MC, Kochi A: Global tuberculosis incidence and mortality during 1990-2000. Bull World Health Organ 1994, 72:213-20.
3. Heymann SJ, Brewer TF, Wilson ME, Colditz GA, Fineberg HV: Pediatric tuberculosis: what needs to be done to decrease morbidity and mortality. Pediatrics 2000, 106:E1.

4. Nelson L, Wells CD: Global epidemiology of childhood tuberculosis. Int J Tuberc Lung Dis 2004, 8(5):636-47.

5. Donald PR: Childhood tuberculosis: out of control? Curr Opin Pulm Med 2002, 8:178-82.

6. Lin YS, Huang YC, Chang LY, Lin TY, Wong KS: Clinical characteristics of tuberculosis in children in the north of Taiwan. J Microbiol Immunol Infect 2005, 38:41-6.

7. Wong KS, Chiu CH, Huang YC, Lin TY: Childhood and adolescent tuberculosis in northern Taiwan: an institutional experience during 1994-1999. Acta Paediatr 2001, 90:943-7.

8. Nelson LJ, Schneider E, Wells CD, Moore M: Epidemiology of childhood tuberculosis in the United States, 1993-2001: the need for continued vigilance. Pediatrics 2004, 114:333-41.

9. Uysal G, Gursoy T, Guven A, Gunindi F, Cuhaci B: Clinical features of extrapulmonary tuberculosis in children. Saudi Med J 2005, 26:750-3.

10. National Tuberculosis Centre: Annual report of national tuberculosis control programme. Ministry of Health, Kathmandu, Nepal 2006.

11. Udani PM: BCG test in the diagnosis of tuberculosis in children. Indian Pediatr 1982, 19:563-81.

12. American Thoracic Society: Targeted tuberculin testing and treatment of latent tuberculosis infection. Am J Respir Crit Care Med 2000, 161: S221-S247.

13. Marais BJ, Gie RP, Schaaf HS, Beyers N, Donald PR, Starke JR: Childhood pulmonary tuberculosis: old wisdom and new challenges. Am J Respir Crit Care Med 2006, 173:1078-90.

14. Marais BJ, Hesseling AC, Gie RP, Schaaf HS, Beyers N: The burden of childhood tuberculosis and the accuracy of community-based surveillance data. Int J Tuberc Lung Dis 2006, 10:259-63.

15. Starke JR, Jacobs RF, Jereb J: Resurgence of tuberculosis in children. J Pediatr 1992, 120:839-55.

16. Bonifachich E, Chort M, Astigarraga A, Diaz N, Brunet B, Pezzotto SM, Bottasso O: Protective effect of Bacillus Calmette-Guerin (BCG) vaccination in children with extra-pulmonary tuberculosis, but not the pulmonary disease. A case-control study in Rosario, Argentina. Vaccine 2006, 24:2894-9.

17. Soysal A, Millington KA, Bakir M, Dosanjh D, Aslan Y, Deeks JJ, Efe S, Staveley I, Ewer K, Lalvani A: Effect of BCG vaccination on risk of Mycobacterium tuberculosis infection in children with household tuberculosis contact: a prospective community-based study. Lancet 2005, 366:1443-51.

18. Eisenhut M, Paranjothy S, Abubakar I, Bracebridge S, Lilley M, Mulla R, Lack $K$, Chalkley D, McEvoy M: BCG vaccination reduces risk of infection with Mycobacterium tuberculosis as detected by gamma interferon release assay. Vaccine 2009, 27:6116-20.

19. Phongsamart W, Kitai I, Gardam M, Wang J, Khan K: A population-based study of tuberculosis in children and adolescents in Ontario. Pediatr Infect Dis J 2009, 28(5):416-9.

20. Maltezou HC, Spyridis P, Kafetzis DA: Extrapulmonary tuberculosis in children. Arch Dis Child 2000, 83:342-46.

21. Peto HM, Pratt RH, Harrington TA, LoBue PA, Armstrong LR: Epidemiology of extrapulmonary tuberculosis in the United States, 1993-2006. Clin Infect Dis 2009, 49:1350-7.

22. Sreeramareddy CT, Panduru KV, Verma SC, Joshi HS, Bates MN: Comparison of pulmonary and extrapulmonary tuberculosis in Nepal-a hospitalbased retrospective study. BMC Infect Dis 2008, 8:8.

23. Graham SM, Gie RP, Schaaf HS, Coulter JB, Espinal MA, Beyers N: Childhood tuberculosis: clinical research needs. Int J Tuberc Lung Dis 2004, 8:648-57.

24. De Villiers RV, Andronikou S, Van de Westhuizen S: Specificity and sensitivity of chest radiographs in the diagnosis of paediatric pulmonary tuberculosis and the value of additional high-kilovolt radiographs. Australas Radiol 2004, 48:148-53.

25. Menzies D: What does tuberculin reactivity after bacille Calmette-Guérin vaccination tell us? Clin Infect Dis 2000, 31:S71-4.

26. Khemiri M, Labessi A, Zouari S, Borgi A, Ben Mansour F, Oubich F, Khaldi F, Barsaoui S: Tuberculosis in childhood: clinical features and problems in diagnosis. Report of 30 cases. Tunis Med 2009, 87:61-7. 
27. Davidson RN: Childhood tuberculosis-problems ahead. Trans $R$ Soc Trop Med Hyg 2000, 94:5-6.

\section{Pre-publication history}

The pre-publication history for this paper can be accessed here:

http://www.biomedcentral.com/1471-2431/10/57/prepub

doi:10.1186/1471-2431-10-57

Cite this article as: Sreeramareddy et al:: Clinico-epidemiological profile and diagnostic procedures of pediatric tuberculosis in a tertiary care hospital of western Nepal-a case-series analysis. BMC Pediatrics 2010 10:57.

Submit your next manuscript to BioMed Central and take full advantage of:

- Convenient online submission

- Thorough peer review

- No space constraints or color figure charges

- Immediate publication on acceptance

- Inclusion in PubMed, CAS, Scopus and Google Scholar

- Research which is freely available for redistribution

Submit your manuscript at www.biomedcentral.com/submit 